\title{
Novel exercise protocol suitable for use on a treadmill or a bicycle ergometer
}

David B Northridge, Stanley Grant, Ian Ford, James Christie, James McLenachan, Derek Connelly, John McMurray, Simon Ray, Esther Henderson, Henry J Dargie

\begin{abstract}
Many exercise protocols are in use in clinical cardiology, but no single test is applicable to the wide range of patients' exercise capacity. A new protocol was devised that starts at a low workload and increases by $15 \%$ of the previous workload every minute. This is the first protocol to be based on exponential rather than linear increments in workload. The new protocol (standardised exponential exercise protocol, STEEP) is suitable for use on either a treadmill or a bicycle ergometer. This protocol was compared with standard protocols in $\mathbf{3 0}$ healthy male volunteers, each of whom performed four exercise tests: the STEEP treadmill and bicycle protocols, a modified Bruce treadmill protocol, and a $20 \mathrm{~W} / \mathrm{min}$ bicycle protocol. During the two STEEP tests the subjects' oxygen consumption rose gradually and exponentially and there was close agreement between the bicycle and the treadmill protocols. A higher proportion of subjects completed the treadmill than the bicycle protocol. Submaximal heart rates were slightly higher during the bicycle test. The STEEP protocol took less time than the modified Bruce treadmill protocol, which tended to produce plateaux in oxygen consumption during the early stages. The $20 \mathrm{~W} / \mathrm{min}$ bicycle protocol does not take account of subjects' body weight and consequently produced large intersubject variability in oxygen consumption.
\end{abstract}

The STEEP protocol can be used on either a treadmill or a bicycle ergometer and it should be suitable for a wide range of patients.

Many different exercise protocols are used in clinical cardiology. Because no single test is suited to the wide range of patients' exercise capacities many centres use two protocolsone for fitter patients and another for more limited patients. This, however, requires a pre-test estimate of exercise capacity, which is not always accurate.

Several features are desirable in any exercise protocol. It should be applicable to a wide range of patients so that assumptions about exercise capacity do not have to be made before the test. The most severely limited patients should be able to exercise for at least 3 minutes, ${ }^{1}$ which necessitates starting at a low workload. On the other hand, the test must not be too long or fatigue and boredom (of both the patient and supervising physician) may become limiting factors. An average duration of 10 minutes has been suggested, ${ }^{23}$ and all patients should reach their maximum by 15 minutes. ${ }^{2}$

A further complication is that various exercise laboratories use different modes of exercise testing: bicycle ergometers predominate in mainland Europe while treadmills are favoured in the United Kingdom and United States. These two modes of exercise have an essential difference: on a treadmill the work performed during each stage is dependent on body weight, while bicycle exercise is weight independent. Bicycle exercise testing therefore needs to be standardised for body weight so that different subjects perform similar relative work at each stage, otherwise larger subjects will have a performance advantage. Most existing bicycle protocols fail to take this into account. During treadmill exercise the patient has to carry his or her own weight and so this mode of exercise testing is automatically standardised.

The aim of this study was to devise a new protocol that would accommodate the full range of patients' exercise capacity and could be used on either a treadmill or a bicycle ergometer.

\section{Subjects and methods}

The cardiopulmonary responses to the new exercise test were compared with standard protocols in 30 healthy male volunteers (mean age 38 years (range 28-55); mean weight $74 \mathrm{~kg}$ (range 57-97)).

\section{EXERCISE PROTOCOLS}

The new protocol was designed to begin at a low workload ( $2 \mathrm{METS}, 7 \mathrm{ml} / \mathrm{kg} / \mathrm{min}$ ) and the initial increments were kept small by increasing the workload by $15 \%$ of the previous stage every minute. This results in an exponential rise in workload, and the highest stage required to test even relatively fit patients is reached after 15 minutes. This is the first protocol to be based on exponential rather than linear increments in workload.

The mathematical model of this new exercise test was translated into a treadmill protocol by means of standard formulas for oxygen consumption derived from treadmill speed and gradient. ${ }^{4}$ At each stage either the treadmill speed or the gradient was increased, never both together. Table 1 shows the resulting STEEP treadmill protocol.

The STEEP test was applied to a bicycle 
ergometer after allowing for body weight. Table 2 was derived, again by means of standard formulas, ${ }^{4}$ to predict the bicycle protocol required to elicit the same relative oxygen consumption as the treadmill protocol for a given body weight (rounded to the nearest $5 \mathrm{~kg}$ ).

\section{METHODS}

Each of the 30 men performed four exercise tests in random order on separate visits at the same time of day in the postabsorptive state. They exercised to symptom limited maximum on a modified Bruce treadmill protocol ${ }^{5}$ and a $20 \mathrm{~W} / \mathrm{min}$ bicycle protocol. ${ }^{6}$ They exercised either to exhaustion or to completion of the 15 minute treadmill and bicycle STEEP protocols. All tests were performed in an air conditioned exercise laboratory at a constant temperature.

A Marquette MAC 2 was used for the treadmill tests and a Bosch ERG 551 electronically braked ergometer was used for the bicycle protocols. Respiratory variables were determined during exercise by an automated gas analysis system (Beckman metabolic measurement cart; classic exercise model system 2) that was calibrated for barometric pressure. Before each test the oxygen and carbon dioxide sensors were calibrated with a standard gas mixture containing $16 \%$ oxygen, $4 \%$ carbon dioxide, and $80 \%$ nitrogen.

The oxygen consumption $\left(\dot{V}_{2}\right)$ for each stage of the various protocols was taken as the average over the last 30 seconds of that stage. Heart rate was taken from the electrocardiogram during the last 10 seconds of each stage. Systolic blood pressure was determined by palpation every 3 minutes.

\section{STATISTICAL ANALYSIS}

The significance of differences in the mean heart rate, $\dot{\mathrm{VO}}_{2}$, and blood pressure between the protocols was determined at each stage by uncorrected paired $t$ tests. The significance after Bonferroni correction for multiple comparisons is also discussed in the text. Repeated measures analysis of variance was not applied because the subjects stopped exercise at different rates on the various protocols; this led to missing data which were "not at random". The significance of differences between the proportions of subjects failing to complete the two STEEP tests was assessed by McNemar's test for comparing correlated proportions.

\section{Results}

AGREEMENT BETWEEN THE TWO STEEP TESTS

Twenty seven men completed the 15 minute STEEP treadmill test and 18 completed the bicycle protocol ( $p<0.005$ ). Figure 1 shows the oxygen consumption during each stage of the two STEEP tests. During both the treadmill and bicycle protocols the subjects' $\mathrm{VO}_{2}$ rose in an exponential manner. There was no significant difference in mean $\mathrm{Vo}_{2}$ for 11 of the 15 stages. The subjects' oxygen consumption was slightly, but statistically significantly, higher for the first three minutes and the final minute of the treadmill test (fig 1). None of the differences was significant after correction for multiple comparisons.

Figure 2 shows the subjects' heart rates during the two STEEP tests. Heart rates were significantly higher during the middle stages of the bicycle test, but the difference was less than 10 beats per minute at every stage. There was no significant difference in blood pressure between the two modes of exercise.

COMPARISON WITH EXISTING PROTOCOLS

Figure 3 compares oxygen consumption during the STEEP treadmill protocol with that during the modified Bruce protocol. The modified Bruce protocol required 19 minutes to complete the range of workloads covered by the STEEP test in 15 minutes. A plateau in $\mathrm{VO}_{2}$ was achieved during the first four stages of the

Table 1 STEEP treadmill protocol

\begin{tabular}{|c|c|c|c|c|c|c|c|c|c|c|c|c|c|c|c|}
\hline & \multicolumn{15}{|c|}{ Stage $(\min ):$} \\
\hline & 1 & 2 & 3 & 4 & 5 & 6 & 7 & 8 & 9 & 10 & 11 & 12 & 13 & 14 & 15 \\
\hline $\begin{array}{l}\text { Speed }(\mathrm{mph}) \\
\text { Speed }(\mathbf{k m} / \mathbf{h}) \\
\text { Elevation }\left({ }^{\circ}{ }_{0}\right)\end{array}$ & $\begin{array}{l}1 \cdot 5 \\
2 \cdot 4 \\
0\end{array}$ & $\begin{array}{l}2 \cdot 0 \\
3 \cdot 2 \\
0\end{array}$ & $\begin{array}{l}2.0 \\
3.2 \\
1.5\end{array}$ & $\begin{array}{l}2 \cdot 0 \\
3 \cdot 2 \\
3\end{array}$ & $\begin{array}{l}2 \cdot 5 \\
4 \cdot 0 \\
3\end{array}$ & $\begin{array}{l}2 \cdot 5 \\
4 \cdot 0 \\
5\end{array}$ & $\begin{array}{l}2 \cdot 5 \\
4 \cdot 0 \\
7\end{array}$ & $\begin{array}{l}3 \cdot 0 \\
4 \cdot 8 \\
7\end{array}$ & $\begin{array}{l}3 \cdot 0 \\
4 \cdot 8 \\
9\end{array}$ & $\begin{array}{r}3 \cdot 0 \\
4 \cdot 8 \\
11\end{array}$ & $\begin{array}{r}3.5 \\
5.6 \\
11\end{array}$ & $\begin{array}{c}3 \cdot 5 \\
5 \cdot 6 \\
13\end{array}$ & $\begin{array}{c}3.5 \\
5.6 \\
16\end{array}$ & $\begin{array}{c}4 \cdot 2 \\
6 \cdot 7 \\
16\end{array}$ & $\begin{array}{l}5 \cdot 0 \\
8 \cdot 0 \\
16\end{array}$ \\
\hline
\end{tabular}

Table 2 STEEP bicycle protocol showing the workload for each of the 15 stages of the protocol as determined by the subject's body weight in kilograms

\begin{tabular}{|c|c|c|c|c|c|c|c|c|c|c|c|c|c|c|c|}
\hline \multirow[b]{2}{*}{ Weight (kg) } & \multicolumn{15}{|c|}{ Stage $(\min )$ : } \\
\hline & 1 & 2 & 3 & 4 & 5 & 6 & 7 & 8 & 9 & 10 & 11 & 12 & 13 & 14 & 15 \\
\hline $\begin{array}{r}50 \\
55 \\
60 \\
65 \\
70 \\
75 \\
80 \\
85 \\
90 \\
95 \\
100\end{array}$ & $\begin{array}{l}15 \\
15 \\
15 \\
20 \\
20 \\
20 \\
25 \\
25 \\
25 \\
25 \\
30\end{array}$ & $\begin{array}{l}20 \\
20 \\
25 \\
25 \\
25 \\
30 \\
30 \\
35 \\
35 \\
35 \\
40\end{array}$ & $\begin{array}{l}25 \\
30 \\
30 \\
35 \\
35 \\
40 \\
40 \\
45 \\
45 \\
50 \\
50\end{array}$ & $\begin{array}{l}30 \\
35 \\
40 \\
40 \\
45 \\
45 \\
50 \\
55 \\
55 \\
60 \\
65\end{array}$ & $\begin{array}{l}40 \\
45 \\
45 \\
50 \\
55 \\
60 \\
65 \\
65 \\
70 \\
75 \\
80\end{array}$ & $\begin{array}{r}50 \\
55 \\
60 \\
65 \\
70 \\
75 \\
80 \\
85 \\
90 \\
95 \\
100\end{array}$ & $\begin{array}{r}60 \\
65 \\
70 \\
80 \\
85 \\
90 \\
95 \\
100 \\
105 \\
115 \\
120\end{array}$ & $\begin{array}{r}70 \\
80 \\
85 \\
90 \\
100 \\
105 \\
115 \\
120 \\
130 \\
135 \\
140\end{array}$ & $\begin{array}{r}85 \\
95 \\
100 \\
110 \\
120 \\
125 \\
135 \\
145 \\
150 \\
160 \\
170\end{array}$ & $\begin{array}{r}95 \\
105 \\
115 \\
125 \\
135 \\
145 \\
155 \\
165 \\
175 \\
180 \\
190\end{array}$ & $\begin{array}{l}110 \\
125 \\
135 \\
145 \\
155 \\
170 \\
180 \\
190 \\
200 \\
215 \\
225\end{array}$ & $\begin{array}{l}125 \\
140 \\
150 \\
165 \\
175 \\
190 \\
200 \\
215 \\
225 \\
240 \\
250\end{array}$ & $\begin{array}{l}145 \\
160 \\
175 \\
190 \\
205 \\
220 \\
235 \\
250 \\
265 \\
280 \\
295\end{array}$ & $\begin{array}{l}170 \\
185 \\
200 \\
220 \\
235 \\
250 \\
270 \\
285 \\
300 \\
320 \\
335\end{array}$ & $\begin{array}{l}185 \\
205 \\
225 \\
240 \\
260 \\
280 \\
295 \\
315 \\
335 \\
350 \\
370\end{array}$ \\
\hline
\end{tabular}


Figure 1 Mean ( $S D$ ) oxygen consumption of 30 healthy men performing the two STEEP protocols. $\dot{V} \mathrm{O}_{2}$, oxygen consumption. $\star_{p}<0.05$ on uncorrected $t$ test.

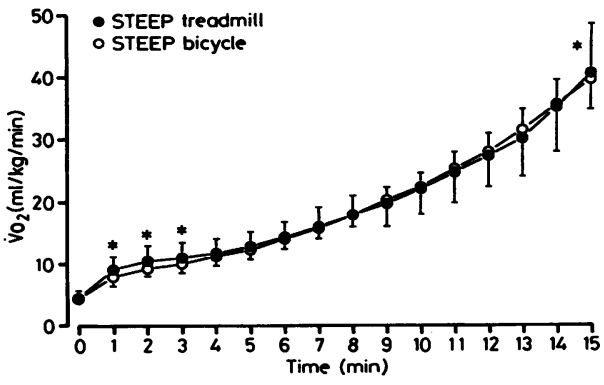

Figure 2 Mean (SD) heart rate of 30 healthy men performing the two $S T E E P$ protocols. * $p<$ 0.05 on uncorrected $t$ test.

Figure 3 Mean (SD oxygen consumption of 30 healthy men performing the two treadmill protocols. $\mathrm{VO}_{2}$, oxygen consumption.

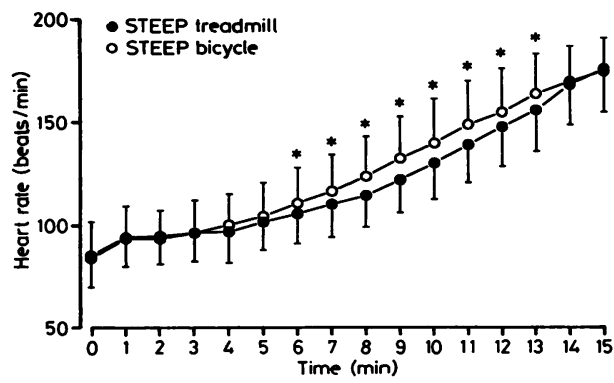

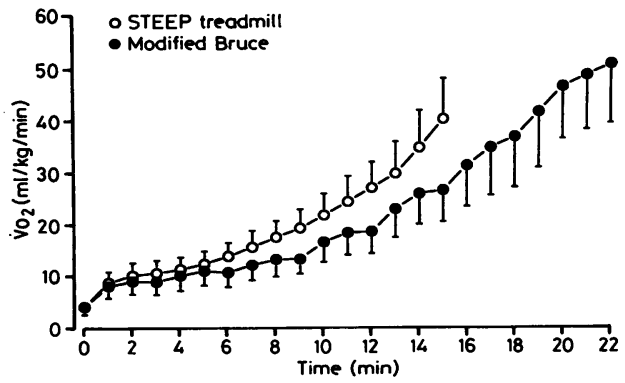

Figure 4 Mean ( $S D$ ) oxygen consumption for 30 healthy men performing the two bicycle protocols. $\dot{V} \mathrm{O}_{2}$, oxygen consumption.

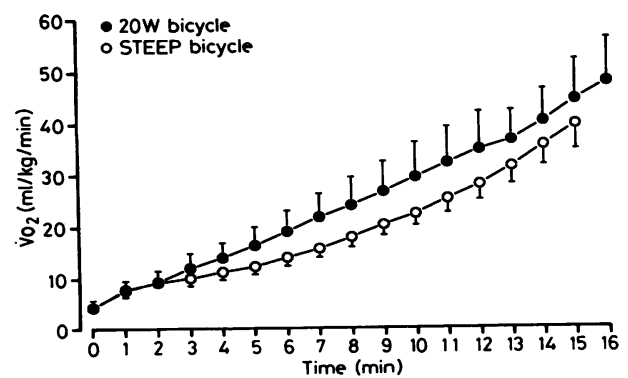

modified Bruce protocol but not during subsequent stages. The mean (SD) exercise time on this protocol was 20 minutes 14 seconds (156 seconds), and the mean (SD) $\dot{\mathrm{Vo}}_{2} \max$ was $45 \cdot 3$ (13.1) $\mathrm{ml} / \mathrm{kg} / \mathrm{min}$.

Figure 4 compares the two bicycle protocols. The mean exercise time on the $20 \mathrm{~W} / \mathrm{min}$ protocol was 12 minutes 29 seconds and the mean (SD) $\dot{\mathrm{VO}}_{2} \max$ was $38.2(10.5) \mathrm{ml} / \mathrm{kg} / \mathrm{min}$. The between subject variability of oxygen consumption at each stage, as reflected by the standard deviation, was less with the STEEP bicycle protocol than with the $20 \mathrm{~W} / \mathrm{min}$ protocol (fig 4).

\section{Discussion}

We have designed a new exercise protocol that is the first to be based on exponential rather than linear increments in workload. The test begins with a low workload and because it uses small, frequent increments it is suitable for even the most severely limited patients. Nevertheless, it is designed to induce cessation of exercise in patients with $\mathrm{VO}_{2}$ max up to $35 \mathrm{ml} /$ $\mathrm{kg} / \mathrm{min}$ within 15 minutes so that boredom and fatigue are not limiting factors. To allow measurement of oxygen consumption over the full 15 minute protocols the STEEP tests were initially validated in healthy men rather than the patient population for which they are designed. Both STEEP tests produced a gradual exponential rise in oxygen consumption in these healthy subjects, and no plateau in the cardiovascular responses was apparent.

For 11 of the 15 stages of the treadmill and bicycle tests the mean $\dot{\mathrm{VO}}_{2}$ was the same. Oxygen consumption was slightly higher during the first 3 minutes of the treadmill protocol, possibly because the initial treadmill speed was considerably slower than the subjects' normal walking pace, causing them to adopt an inefficient gait. $\dot{\mathrm{VO}}_{2}$ was also higher on the treadmill during the final stage of exercise. This may be because some subjects performing the bicycle test had already reached their $\mathrm{VO}_{2}$ max and were therefore unable to increase their oxygen consumption further during the last stage of the protocol.

Our finding that the $\mathrm{Vo}_{2}$ max with the $20 \mathrm{~W} /$ min bicycle protocol was lower than with the modified Bruce test accords with previous studies that showed $\dot{\mathrm{VO}}_{2} \max$ was $6 \%-17 \%$ lower on a bicycle ergometer than on a treadmill. ${ }^{2-9}$ Possible reasons for a lower $\dot{\mathrm{VO}}_{2} \max$ on a bicycle ergometer include an early end to exercise because of localised fatigue and pain in the quadriceps. ${ }^{10}$ In addition, the maximum cardiac output was lower during bicycle exercise, ${ }^{7}$ and this resulted in a lower $\dot{\mathrm{Vo}}_{2}$ max because oxygen consumption is proportional to cardiac output. ${ }^{112}$ During submaximal stages the heart rate during the STEEP bicycle protocol was higher than during the treadmill protocol, despite similar oxygen consumption. This suggested a lower stroke volume during bicycle exercise as was reported in previous studies. ${ }^{101314}$

Many existing protocols have relatively long stages of two or three minutes each in an attempt to produce a plateau of oxygen consumption at each stage. The time taken to reach a steady state is variable, however, and depends on the physical fitness of the subject and the relative work intensity. ${ }^{1315}$ The effect of this was illustrated in this study: during the modified Bruce protocol a steady state was reached rapidly during the early stages but not at all during later stages. Thus a true steady state may not be achieved during the the final stage of an exercise test. Another problem with 
tests consisting of a few prolonged stages is that patients become familiar with the protocol during repeat testing and may repeatedly stop exercising at the same stage. This learning effect may mask improvement with treatment. ${ }^{3}$ We therefore designed a protocol with small, frequent increases in workload, as recommended by previous researchers. ${ }^{216}$ This type of protocol is very useful if submaximal exercise testing is planned later. When a protocol with small, frequent increases in workload has been used for a maximal test, it is possible to choose a stage at $60 \%-70 \%$ of that subject's $\mathrm{Vo}_{2} \max$ for a subsequent submaximal test. A further advantage of the STEEP treadmill test over existing treadmill protocols is that it avoids simultaneous increases in speed and gradient which can unsettle patients. ${ }^{17}$

The mean exercise time of 12 minutes 29 seconds for the $20 \mathrm{~W} / \mathrm{min}$ bicycle protocol was appropriate for these normal subjects; the test would be too short for severely limited patients, however. Furthermore, because body weight is not taken into account, the oxygen consumption at each stage varied considerably between subjects. With the $20 \mathrm{~W} / \mathrm{min}$ bicycle protocol it is therefore not possible to determine whether a patient's exercise time is impaired or to measure the degree of impairment without correction for body weight or direct measurement of oxygen consumption during the test. The STEEP bicycle test takes account of body weight and therefore produces less interpatient variability.

We designed a new protocol based on short stages with exponential increments in workload. The potential advantage of this protocol is that it is suitable for a wide range of patients. The most severely limited patients should manage the initial low workloads, while the exponential rise in workload terminates the test within 15 minutes before boredom and fatigue become limiting factors. The treadmill test is unlikely to intimidate patients because the increments are small and simultaneous increases in speed and gradient are avoided. The test can also be used on a bicycle ergometer if an allowance is made for body weight. In healthy subjects we obtained close agreement between the mean oxygen consumptions for each stage with both modes of exercise. It remains to be seen whether this will be true in a representative patient population.

DBN is a British Heart Foundation Junior Research Fellow. We thank Niall MacFarlane for technical assistance.

1 Redwood DR, Rosing DR, Goldstein RE, Beiser D, Epstein $S E$. Importance of the design of an exercise protocol in the evaluation of patients with angina pectoris. Circulation 1971;43:618-28.

2 Buchfuhrer MJ, Hansen JE, Robinson TE, Sue DY, Wasserman $\mathrm{K}$, Whipp BJ. Optimizing the exercise protocol for cardiopulmonary assessment. J Appl Physio 1983;55:1558-64.

3 Webster MWI, Sharpe DN. Exercise testing in angina pectoris: the importance of protocol design in clinical trials. Am Heart $J$ 1989;117:505-8.

4 American College of Sports Medicine. Guidelines for exercise testing and prescription. Philadelphia: Lea and Febiger, 1986.

5 Sheffield LT. Exercise stress testing. In: Braunwald W, ed. Diseases of the heart. 3rd ed. Philadelphia: WB Saunders, 1988.

6 Detry JMR, Kapita BM, Cosyns J, Sotiaux B, Brasseur LA Rousseau MF. Diagnostic value of history and maximal exercise electrocardiography in men and women suspecexercise electrocardiography in men and women suspec-

7 Faulkner JA, Roberts DE, Elk RL, Conway J. Cardiovascular responses to submaximum and maximum effor cycling and running. $J$ Appl Physiol 1971;30:457-61.

8 Hermansen L, Ekblom B, Saltin B. Cardiac output during submaximal and maximal treadmill and bicycle exercise. $J$ Appl Physiol 1970;29:82-6.

9 Miyamura $M$, Honda $Y$. Oxygen intake and cardiac output during maximal treadmill and bicycle exercise. $J A p p l$ Physiol 1972;32:185-8.

10 Miles DS, Critz JB, Knowlton RG. Cardiovascular, metabolic and ventilatory responses of women to equivalent cycle ergometer and treadmill exercise. Med Sci Sports Exerc 1980;12:14-9.

11 McArdle WD, Katch FI, Katch VL. Exercise physiology, energy, nutrition and human performance. Philadelphia: Lea and Febiger, 1986.

12 Epstein SE, Beiser GD, Stampfer $M$, Robinson BF Braunwald $E$. Characterization of the circulatory respons to maximal upright exercise in normal subjects and patients with heart disease. Circulation 1967;35:1049-62.

13 Whipp BJ, Wasserman $\mathrm{K}$. Oxygen uptake kinetics for various intensities of constant work-load. $J$ Appl Physiol 1972;33:351-6.

14 Niederberger M, Bruce RA, Kusumi F, Whitkanack S Disparities in ventilatory and circulatory responses to bicycle and treadmill exercise. Br Heart $J 1974 ; 36: 377-82$.

15 Hickson RC, Bronze HA, Holloszy JO. Faster adjustment of oxygen uptake to the energy requirement of exercise in the trained state. J Appl Physiol 1978;44:877-81.

16 Áström H, Jonsson B. Design of exercise test, with special reference to heart patients. Br Heart J 1976;38:289-96.

17 Pollock ML, Wilmore JH, Fox SM. Exercise in health and disease. Philadelphia: WB Saunders, 1984. 